CLINICAL STUDY

\title{
Sleep apnoea syndrome is highly prevalent in acromegaly and only partially reversible after biochemical control of the disease
}

\author{
Maria Vittoria Davi', Luca Dalle Carbonare, Andrea Giustina ${ }^{1}$, Marcello Ferrari, Anna Frigo, Vincenzo Lo Cascio \\ and Giuseppe Francia \\ Clinic of Internal Medicine D, Department of Biomedical and Surgical Sciences, University of Verona, Policlinico GB Rossi, Piazzale LA Scuro, 37134 \\ Verona, Italy and ${ }^{1}$ Department of Medical and Surgical Sciences, University of Brescia, Brescia, Italy \\ (Correspondence should be addressed to MV Davi'; Email: mariavittoria.davi@azosp.vr.it)
}

\begin{abstract}
Background: Whether sleep apnoea syndrome (SAS) subsides after biochemical and clinical remission of acromegaly is controversial.

Objective: To assess the presence of SAS in a cohort of acromegalic patients, which included a subgroup with active disease and a subgroup in remission, and to evaluate clinical and biochemical independent predictors of SAS.

Design: Cross-sectional and longitudinal study.

Setting: Italian university department of internal medicine.

Patients: About 36 acromegalic patients: 18 active and 18 controlled.

Measurements: Polysomnography was performed in all patients and repeated in six with active acromegaly and SAS after achieving disease control. Echocardiographic parameters were also measured.

Results: The prevalence of SAS was $47 \%$ in the overall acromegalic population: $56 \%$ in the active group and $39 \%$ in the controlled one. In a multivariate analysis IGF1, male gender, age, body mass index, and disease duration were associated with SAS. Impaired glucose tolerance or diabetes was more prevalent in patients with SAS, particularly in the severe cases. Among the six patients of the longitudinal study, five showed improvement of SAS, but none recovered. No correlation was found between echocardiographic parameters and severity of SAS.

Conclusion: SAS can persist after recovery of acromegaly in several patients. Given the negative prognostic significance of this respiratory disorder, polysomnography should be included as routine procedure in the work-up of the acromegaly, even if in remission, being mandatory in those patients considered at high risk (elderly males, overweight, diabetic). Appropriate intensive treatment should be implemented to minimize the clinical impact of SAS in acromegaly.
\end{abstract}

European Journal of Endocrinology 159 533-540

\section{Introduction}

Sleep apnoea syndrome (SAS) is considered a common disorder in acromegaly, its frequency ranging from 45 to $80 \%$ of patients, according to different series (1-5). This severe complication represents an additional risk factor for cardiovascular disease and may contribute to the increased mortality observed in acromegaly (6-11).

Obstructive SAS is the prevailing form in acromegaly, while the central and mixed types are less frequent. Craniofacial deformations, hypertrophy of the pharyngeal soft tissue, macroglossia and mucosal thickening of the upper airways and bronchi are the main causes of the obstructive form. The pathogenesis of the central SAS is based on the central inhibition of the breathing centre probably due to the elevated levels of GH/IGF1 or to the enhanced somatostatin tone (1). The correlation between GH/IGF1 serum levels and severity of SAS is controversial and it is still unknown whether this comorbidity subsides after biochemical remission of the disease.

Many studies showed higher frequency of SAS in active acromegalic patients with a positive correlation with GH/IGF1 levels $(3,12,13)$. Conversely, in the study of Grunstein et al. (1) only the presence of central apnoea (CA), but not the degree of sleep apnoea, was associated with the disease activity. Risk factors for SAS were ageing $(3,14-17)$, male gender $(4,18)$, body mass index (BMI) $(16,17)$, disease duration (18), neck circumference $(3,14)$ and tongue size $(16,19,20)$.

So far conflicting results have been reported regarding the reversibility of SAS after surgery or medical therapy. Rosenow et al. (14) found a relative high frequency of SAS in patients with treated acromegaly, at least of $21 \%$, with a positive correlation with GH/IGF1 levels, age as well as neck and index-finger 
circumference as measures of soft tissue hypertrophy. Some studies showed significant improvement or cure of SAS after adenomectomy (18, 21-23), while others found persisting nocturnal breathing abnormalities (24) or sleep apnoea in patients previously treated with pituitary surgery (4) or only slight to moderate improvement despite normalized or decreased hormonal levels (25) probably due to the irreversible changes of the craniofacial region and upper respiratory tract (5, $15,19,26)$. Finally, there are many reports of relief of SAS during treatment with s.c. or long acting release (LAR) octreotide $(16,20,26,27)$, although SAS can persist after normalization of hormonal levels $(26,28)$.

The aim of this study was to assess the presence of SAS in a cohort of acromegalic patients which includes a subgroup with active disease and a subgroup in clinical and biochemical remission and to evaluate which clinical and biochemical parameters may independently predict the risk of SAS in acromegaly.

\section{Patients and methods}

This is a cross-sectional and longitudinal study carried out in a cohort of acromegalic patients recruited from a University Center between 2001 and 2007.

\section{Cross-sectional study}

Thirty-six patients (18 women, 18 men, mean (s.D.) age 52.11 (13.1) years) were enrolled in this study, after giving written informed consent. The diagnosis of acromegaly was established on the basis of high serum GH levels, not suppressible below $1 \mathrm{ng} / \mathrm{ml}$ after oral glucose load (in non-diabetic patients), and of high plasma IGF1 levels for age and sex (29).
Eighteen out of 36 patients (mean (s.D.) age 55.4 (14.9) years) were affected by active disease (9 women and 9 men, mean s.D. GH 20.7 (26.7) ng/ml, mean s.D. IGF1 $551.7(220.1) \mathrm{ng} / \mathrm{ml}): 8$ naïve, 4 after surgery alone, 1 plus radiotherapy, 1 plus radiotherapy and somatostatin analogues, 2 plus somatostatin analogues and 1 with cabergoline without radiotherapy, 1 with somatostatin analogues alone. The estimated median duration of disease activity from the onset of the symptoms to the time of polysomnography was 4.5 years (range 1-21 years). The mean (s.D.) BMI was 25.4 (3.7) $\mathrm{kg} / \mathrm{m}^{2}$. Ten patients had arterial hypertension, treated with antihypertensive drugs. Seven patients had impaired glucose tolerance (IGT), whereas three had diabetes mellitus. Five patients had one or more pituitary hormone insufficiency, on adequate substitutive therapy and stable control (Tables 1 and 2).

Eighteen out of 36 patients (nine women and nine men, mean (s.D.) age 48.8 (10.4) years; mean (s.D.) GH 0.8 (0.6) $\mathrm{ng} / \mathrm{ml}$, mean (S.D.) IGF1 $181.5(56.2) \mathrm{ng} / \mathrm{ml})$ had been definitely cured by transsphenoidal surgery alone (six cases) or plus radiotherapy (three cases) or had achieved biochemical remission on therapy with somatostatin analogues (nine cases), given alone (one case), after incomplete resection of the pituitary adenoma (three cases), plus radiotherapy (five cases). The estimated median duration of disease activity from the onset of symptoms to the normalization of GH/IGF1 was 4 years (range 1-14 years). The median remission duration, calculated from the time of normalization of GH/IGF1 levels to the time of polysomnography was 6.5 years (range 1-13 years). The mean (s.D.) BMI was 27.6 (5) $\mathrm{kg} / \mathrm{m}^{2}$. Six patients had arterial hypertension, treated with antihypertensive drugs. Three patients had IGT, whereas two had diabetes mellitus. Nine patients had one or more pituitary hormone insufficiency, on adequate substitutive therapy and stable control (Tables 3 and 4).

Table 1 Clinical characteristics of active acromegalic patients.

\begin{tabular}{|c|c|c|c|c|c|c|c|c|}
\hline Patient & Age (years) & Sex & BMI $\left(\mathrm{kg} / \mathrm{m}^{2}\right)$ & GH $(\mathrm{ng} / \mathrm{ml})$ & IGF1 (ng/ml) & Therapy & Disease (years) & Comorbidities \\
\hline 1 & 73 & $\mathrm{~F}$ & 28.6 & 2.5 & 244 & S-SA & 9 & DM \\
\hline 2 & 49 & $\mathrm{~F}$ & 24.0 & 7.3 & 275 & S-CA & 10 & \\
\hline 3 & 46 & $\mathrm{M}$ & 27.2 & 87.8 & 832 & Naïve & 3 & AH-IGT-PI \\
\hline 4 & 54 & $\mathrm{M}$ & 26.8 & 3.8 & 611 & S & 14 & AH-IGT-PI \\
\hline 5 & 46 & $\mathrm{M}$ & 25.4 & 9.0 & 832 & SA & 4 & AH-DM \\
\hline 6 & 54 & $\mathrm{~F}$ & 21.5 & 6.9 & 275 & S-SA & 27 & AH-IGT \\
\hline 7 & 48 & $\mathrm{~F}$ & 22.6 & 72.0 & 832 & S-SA-RT & 8 & $\mathrm{AH}-\mathrm{IGT}$ \\
\hline 8 & 53 & M & 27.8 & 1.5 & 344 & S & 2 & $\mathrm{PI}$ \\
\hline 9 & 68 & $\mathrm{~F}$ & 26.0 & 6.1 & 595 & S-RT & 11 & AH-IGT-PI \\
\hline 10 & 44 & $\mathrm{M}$ & 24.0 & 3.8 & 565 & Naïve & 1 & $\mathrm{AH}$ \\
\hline 11 & 61 & M & 27.0 & 10.4 & 458 & S & 12 & $\mathrm{PI}$ \\
\hline 12 & 38 & $\mathrm{~F}$ & 23.0 & 10.0 & 702 & Naïve & 6 & \\
\hline 13 & 28 & $\mathrm{~F}$ & 18.0 & 29.6 & 504 & Naïve & 3 & \\
\hline 14 & 70 & $\mathrm{~F}$ & 35.0 & 8.1 & 824 & Naïve & 4 & $\mathrm{AH}-\mathrm{IGT}$ \\
\hline 15 & 46 & $\mathrm{M}$ & 27.7 & 66.2 & 725 & Naïve & 5 & IGT \\
\hline 16 & 79 & $M$ & 22.7 & 3.7 & 191 & $S$ & 2 & $\mathrm{AH}$ \\
\hline 17 & 54 & M & 27.7 & 13.6 & 458 & Naïve & 3 & DM \\
\hline 18 & 86 & $\mathrm{~F}$ & 22.6 & 30.6 & 664 & Naïve & 1.2 & $\mathrm{AH}$ \\
\hline
\end{tabular}

S, surgery; AH, arterial hypertension; SA, somatostatin analogues; IGT, impaired glucose tolerance; CA, cabergoline; DM, diabetes mellitus; RT, radiotherapy; $\mathrm{PI}$, pituitary insufficiency. 
Table 2 Polysomnographic parameters of active acromegalic patients.

\begin{tabular}{lclcc}
\hline Patient & HP & CA & OA & AHI \\
\hline 1 & 7.2 & 0.5 & 19 & 26.7 \\
2 & 0.6 & 0.3 & 0 & 0.9 \\
3 & 18.2 & 6.7 & 0.7 & 25.6 \\
4 & 4.9 & 1.7 & 0.5 & 7.1 \\
5 & 2 & 0 & 1 & 2 \\
6 & 0 & 0 & 0 & 0 \\
7 & 2.8 & 0 & 0 & 2.8 \\
8 & 4.5 & 1 & 18.5 & 24 \\
9 & 0.6 & 0.3 & 0.1 & 1 \\
10 & 0 & 0 & 0 & 0 \\
11 & 3.9 & 0 & 1.4 & 5.3 \\
12 & 0 & 0 & 0 & 0 \\
13 & 0.7 & 0 & 0.1 & 0.8 \\
14 & 17.8 & 0 & 56 & 73.8 \\
15 & 17 & 0.8 & 1.2 & 19.1 \\
16 & 15.5 & 3 & 9 & 27.5 \\
17 & 20 & 0 & 40 & 60 \\
18 & 8 & 0.2 & 29.6 & 37.8 \\
\hline
\end{tabular}

HP, hypopnoea; CA, central apnoea; OA, obstructive apnoea; $A H I$, apnoea/hypopnoea index.

\section{Longitudinal study}

Out of the ten patients with active acromegaly and SAS, six male patients (mean (S.D.) age 56.5 (12.4) years) repeated the polysomnographic study after achievement of biochemical control of the disease (complete in five, near complete in one). Three were naïve and three had already undergone surgery. The estimated median duration of disease from the onset of the symptoms to the time of polysomnography was 3 years (range 2-12 years). The remission was obtained by surgery alone in two patients, plus radiotherapy in one, plus somatostatin analogue in two, with somatostatin analogues alone in one. The median remission time was 3.5 years (range 1.4-4 years).
The mean (S.D.) of GH and IGF1 in active phase was respectively 30.5 (37.0) and $501.3(238.6) \mathrm{ng} / \mathrm{ml}$, and during the disease control was respectively 2.0 (1.5) and $164.2(86.6) \mathrm{ng} / \mathrm{ml}$, whereas BMI was respectively 27 (2) $\mathrm{kg} / \mathrm{m}^{2}$ and $27.6(3.54) \mathrm{kg} / \mathrm{m}^{2}$. Two patients had arterial hypertension, treated with antihypertensive drugs, two patients had IGT, one diabetes mellitus and two pituitary insufficiency on adequate substitutive therapy (Table 5).

\section{Polysomnographic study}

Overnight polysomnography, recording airflow at nose and mouth, chest and abdominal movement by plethysmograph, body position, heart rate, oxygen saturation and snoring, was performed between 2300 and $0800 \mathrm{~h}$ at least once in all 36 acromegalic patients with a portable device (Embletta-pds Somnologica, SapioLife, Reykjavik, Iceland). An apnoea was defined as a ten second breathing pause and a hypopnoea (HP) as a ten second event with continued breathing but reduced ventilation by at least 50\% compared with the previous baseline during sleep. Apnoeas were further classified in obstructive apnoeas (OA): cessation of airflow in the presence of respiratory effort and CAs: cessation of airflow with the absence of respiratory effort. The diagnosis of SAS was established by the apnoea/HP index (AHI), calculated as the average of apnoeic and hypopnoeic events per hour of sleep. According to the literature (30), an $\mathrm{AHI} \geq 5 / \mathrm{h}$ was considered suggestive of SAS, defined as mild with AHI 5-14/h, moderate with AHI 15-30/h and severe with AHI > 30/h.

\section{Echocardiographic study}

Transthoracic M-mode, 2-dimensional, pulsed Doppler and Color-doppler echocardiographic study was

Table 3 Clinical characteristics of controlled acromegalic patients.

\begin{tabular}{|c|c|c|c|c|c|c|c|c|c|}
\hline Patient & $\begin{array}{c}\text { Age } \\
\text { (years) }\end{array}$ & Sex & $\begin{array}{c}\text { BMI } \\
\left(\mathrm{kg} / \mathrm{m}^{2}\right)\end{array}$ & $\underset{(\mathrm{ng} / \mathrm{ml})}{\mathbf{G H}}$ & $\begin{array}{c}\text { IGF1 } \\
(\mathrm{ng} / \mathrm{ml})\end{array}$ & Therapy & $\begin{array}{c}\text { Disease } \\
\text { (years) }\end{array}$ & $\begin{array}{c}\text { Remission } \\
\text { (years) }\end{array}$ & Comorbidities \\
\hline 1 & 28 & $\mathrm{M}$ & 40.0 & 0.38 & 206 & S-SA-RT & 1 & 7 & IGT-PI \\
\hline 2 & 69 & $\mathrm{~F}$ & 31.0 & 0.13 & 76 & S-SA & 2 & 1 & $\mathrm{AH}-\mathrm{DM}$ \\
\hline 3 & 56 & $\mathrm{~F}$ & 30.4 & 0.53 & 176 & S-RT & 2.9 & 10 & AH-IGT-PI \\
\hline 4 & 59 & $\mathrm{M}$ & 24.0 & 0.26 & 115 & S-SA & 11 & 13 & \\
\hline 5 & 46 & $\mathrm{M}$ & 25.0 & 0.16 & 145 & S & 1 & 1 & $\mathrm{AH}$ \\
\hline 6 & 56 & $\mathrm{M}$ & 25.4 & 1.16 & 221 & SA & 8 & 5 & AH-DM \\
\hline 7 & 56 & $\mathrm{M}$ & 32.2 & 0.48 & 290 & S-SA & 14 & 10 & IGT \\
\hline 8 & 48 & $\mathrm{~F}$ & 21.5 & 0.30 & 260 & S & 1 & 1 & \\
\hline 9 & 60 & $M$ & 24.4 & 1.00 & 153 & $S$ & 1 & 9 & $\mathrm{PI}$ \\
\hline 10 & 44 & $\mathrm{~F}$ & 30.8 & 1.07 & 214 & S-SA-RT & 3 & 6 & PI \\
\hline 11 & 50 & M & 26.6 & 0.27 & 153 & S-RT & 6 & 12 & \\
\hline 12 & 53 & $\mathrm{~F}$ & 26.6 & 0.20 & 198 & $\mathrm{~S}$ & 1 & 1 & $\mathrm{AH}$ \\
\hline 13 & 32 & M & 22.6 & 1.20 & 214 & $S$ & 4 & 1 & PI \\
\hline 14 & 50 & $\mathrm{~F}$ & 27.0 & 0.90 & 221 & S-SA-RT & 8 & 10 & $\mathrm{PI}$ \\
\hline 15 & 39 & $\mathrm{~F}$ & 20.0 & 1.40 & 183 & $S$ & 4 & 1 & \\
\hline 16 & 49 & M & 25.3 & 1.60 & 214 & S-SA-RT & 7 & 10 & $\mathrm{PI}$ \\
\hline 17 & 49 & $\mathrm{~F}$ & 28.4 & 0.65 & 92 & S-RT & 11 & 10 & $\mathrm{AH}-\mathrm{PI}$ \\
\hline 18 & 35 & $\mathrm{~F}$ & 35.0 & 2.50 & 137 & S-SA-RT & 4 & 3 & $\mathrm{PI}$ \\
\hline
\end{tabular}

$\mathrm{S}$, surgery; $\mathrm{AH}$, arterial hypertension; SA, somatostatin analogues; IGT, impaired glucose tolerance; RT, radiotherapy; DM, diabetes mellitus; PI, pituitary insufficiency. 
Table 4 Polysomnographic parameters of controlled acromegalic patients.

\begin{tabular}{lcllc}
\hline Patient & HP & CA & OA & AHI \\
\hline 1 & 20 & 8.3 & 6.1 & 34.4 \\
2 & 0.6 & 0 & 0 & 0.6 \\
3 & 17.1 & 6.5 & 7.9 & 31.5 \\
4 & 12.2 & 2.6 & 1.6 & 16.4 \\
5 & 0.7 & 0.3 & 0 & 1 \\
6 & 5 & 1.5 & 6.7 & 13.2 \\
7 & 7.7 & 0.5 & 3.8 & 12 \\
8 & 0.1 & 0 & 0.3 & 0.4 \\
9 & 0.6 & 0 & 0 & 0.6 \\
10 & 2.5 & 0 & 0 & 2.5 \\
11 & 4.6 & 0 & 0 & 4.6 \\
12 & 0.5 & 0 & 0 & 0.5 \\
13 & 4.6 & 4.3 & 0 & 8.9 \\
14 & 1.8 & 0.1 & 0 & 1.9 \\
15 & 0.3 & 0 & 0 & 0.3 \\
16 & 3.4 & 0 & 1 & 4.4 \\
17 & 6.5 & 0 & 0.2 & 6.7 \\
18 & 2.4 & 0 & 0 & 2.4 \\
\hline
\end{tabular}

HP, hypopnoea; CA, central apnoea; OA, obstructive apnoea; $A H I$, apnoea/hypopnoea index.

performed, according to the recommendations of the American Society of Echocardiography (31), determining inter-ventricular septum thickness (IVST), posterior wall thickness (PWT), left atrial dimension (LAD), left ventricular internal end-diastolic diameter (LVID), left ventricular systolic diameter (LVSD) and left ventricular mass (LVM) calculated by Devereux's Formula (32). LVM index (LVMi) was obtained by dividing LVM by body surface area. LV hypertrophy was considered when LVM corrected for body surface area (LVMi) was $\geq 135 \mathrm{~g} / \mathrm{m}^{2}$ in males and $\geq 110 \mathrm{~g} / \mathrm{m}^{2}$ in females. This procedure was performed at the time of polysomnography.

\section{Hormone assays}

Serum GH and IGF1 were determined by chemiluminescent immunometric assay (Immulite, DPC, Los Angeles, CA, USA). The analytical sensitivity of GH and IGF 1 assay were respectively $0.01 \mathrm{ng} / \mathrm{ml}$ and $20 \mathrm{ng} / \mathrm{ml}$ and the intra-assay precision were respectively $5.6 \%$ and $11.5 \%$ in the standard curve range. Age related reference ranges (mean \pm 2 s.D.) for IGF1 were $114-305 \mathrm{ng} / \mathrm{ml}$ for 20-40 years, 76-229 $\mathrm{ng} / \mathrm{ml}$ for $41-65$ years and $61-$ $183 \mathrm{ng} / \mathrm{ml}$ for $>65$ years. Standards were calibrated against World Health Organization (WHO 80/505 $(1 \mathrm{mg}=2.6 \mathrm{IU})) 1$ st international reference preparation (IRP) for GH and against WHO 87/518 for IGF1.

\section{Statistical analysis}

The results are expressed as means (S.D.). Two-sample Student's $t$-test was used to verify statistical differences between means. Multifactor ANOVA was used when appropriate. Linear (univariate and stepwise multiple regression analysis) and logistic regression analyses were used to evaluate the relationship between the variables considered. The $\chi^{2}$ test was used to compare frequencies. Values of $P<0.05$ were considered statistically significant. Statistical analyses were performed by using SPSS for Windows version 14.0 (SPSS Inc., Chicago, IL, USA).

\section{Results}

\section{Cross-sectional study}

On the basis of AHI 17 patients out of the whole population ( $47 \%$ ), 7 out of 18 controlled subjects (39\%) and 10 out of the 18 subjects with active disease (56\%) were found to be affected by SAS.

There was no significant difference in GH/IGF1 levels between patients with or without SAS in each subgroup (active acromegalic patients: mean (s.D.) GH 16.5 (26.5) $\mathrm{ng} / \mathrm{ml}$ versus 18.1 (23.2) ng/ml; IGF1 489.3 (234.3) $\mathrm{ng} / \mathrm{ml}$ versus $572.5(218.3) \mathrm{ng} / \mathrm{ml}$; controlled patients GH $0.66(0.37) \mathrm{ng} / \mathrm{ml}$ versus $0.86(0.75) \mathrm{ng} / \mathrm{ml}$, IGF1 $187(67.2) \mathrm{ng} / \mathrm{ml}$ versus $177.6(50.4) \mathrm{ng} / \mathrm{ml})$.

Five patients had severe SAS (mean (S.D.) AHI 47.5 (18.5)), six moderate (mean (s.D.) AHI 23.2 (4.58)) and six mild (mean (s.D.) AHI 8.9 (3.1)). The severe and moderate form of SAS was more frequent in the active group (respectively 3 and 5) when compared with the controlled group ( 2 and 1 ), while the mild form was prevalent in the inactive group (4 vs 2 ; Fig. 1 ).

The number of $\mathrm{OA}$ was significantly higher in the group with active acromegaly than the controlled group (mean (s.D.) $17.6(19.2) / \mathrm{h}$ vs $3.8(3.2) / \mathrm{h} ; P=0.009)$. Also AHI mean values were higher in subjects with active disease, even though the difference was not statistically significant (mean (s.D.) 30.7 (21.6) vs 17.6 (11.0); Fig. 2).

Most patients with SAS showed OA (mean (s.D.) 11.9 (16.1)/h), or HP (mean (s.D.) $11.2(6.2) / \mathrm{h}$ ), whereas only three had significant CA (mean (s.D.) $7.2(0.9) / \mathrm{h})$.

\section{Predictive factors: anthropometric and disease-specific parameters}

SAS occurred significantly more frequently in male than in female patients ( 12 men, $70.6 \%, 5$ women, $29.4 \%, P=0.019)$. Age significantly correlated with OA $(P=0.004)$ and AHI $(P=0.025)$, considering the whole population. Moreover, BMI significantly correlated with AHI $(P=0.01)$, HP $(P=0.003)$ and CA $(P=0.045)$. Disease duration correlated with AHI $(P=0.012)$ and HP $(P=0.021)$ in the group of patients with SAS.

In a multivariate analysis, in the overall population, age and BMI were independently associated with AHI (respectively $P=0.01, P=0.002, r^{2} 0.34$ ) and $\mathrm{OA}$ (respectively $P=0.003, P=0.002, r^{2} 0.38$ ), BMI also 
with HP $\left(P=0.001, r^{2} 0.28\right)$, whereas IGF1 only with OA $\left(P=0.048, r^{2} 0.38\right)$.

In the group of patients with SAS, disease duration was independently associated with AHI $(P=0.003$, $\left.r^{2} 0.54\right)$ and $\mathrm{OA}\left(P=0.015, r^{2}=0.57\right)$.

No correlation was found between AHI, OA, CA, HP and remission time considering the controlled group.

\section{Effect of treatments}

Among the group of controlled acromegaly no difference was found regarding the modality of treatment between the 11 patients without SAS (five only surgery, one surgery with radiotherapy, one surgery plus somatostatin analogues, four surgery plus radiotherapy and somatostatin analogues) and the seven patients with SAS (one only surgery, two surgery plus radiotherapy, two surgery plus somatostatin analogues, one surgery plus radiotherapy and somatostatin analogues, one only somatostatin analogues).

\section{Effect of comorbidities}

The presence of arterial hypertension did not correlate with CA, OA, HP and AHI.

Patients with IGT or diabetes had significantly higher number of HP (mean (s.D.) 12.4 (6.6) events/h versus 7.9 (4.4) events/h, $P=0.007$ ) and CA (mean (s.D.) 2.57 (3.25) vs $1.58(1.7)$ events/h $P=0.048)$. Also AHI mean values were higher in subjects with IGT/diabetes, even though the difference was not statistically significant (mean (s.D.) 29.1 (22.4) vs 18.1 (12.2)).

The prevalence of diabetes or IGT was higher in the group with SAS (10 out of 17 patients) when compared with the group without SAS ( 5 out of 19 patients). This trend did not reach statistical significance $(P=0.06)$. Moreover, diabetes and IGT were more prevalent in the group with severe SAS (4 out of 5 patients) when compared with both groups with mild and moderate SAS ( 3 out of 6 patients).

\section{Echocardiographic parameters}

Seventeen out of 31 patients had left ventricular hypertrophy (mean (s.D.) LVMi 143.99 (14.45) g/m in 7 women, $167.48(18.12) \mathrm{g} / \mathrm{m}^{2}$ in eight men). No statistical difference was found in LVMi between patients with or without SAS (respectively mean (S.D.) $129.86(33.41) \mathrm{g} / \mathrm{m}^{2}$ vs $117.64(44.16) \mathrm{g} / \mathrm{m}^{2}$, NS). Correlation was found between IGF 1 and PWT $(P=0.035)$ and $\operatorname{LAD}(P=0.037)$ and between $\mathrm{GH}$ and LVMi $(P=0.036)$. No correlation was found between echocardiographic parameters (IVST, PWT, LVID, LVSD, LVMi) and AHI, HP, OA and CA. No statistical difference between patients with or without SAS was observed in echocardiographic parameters. 


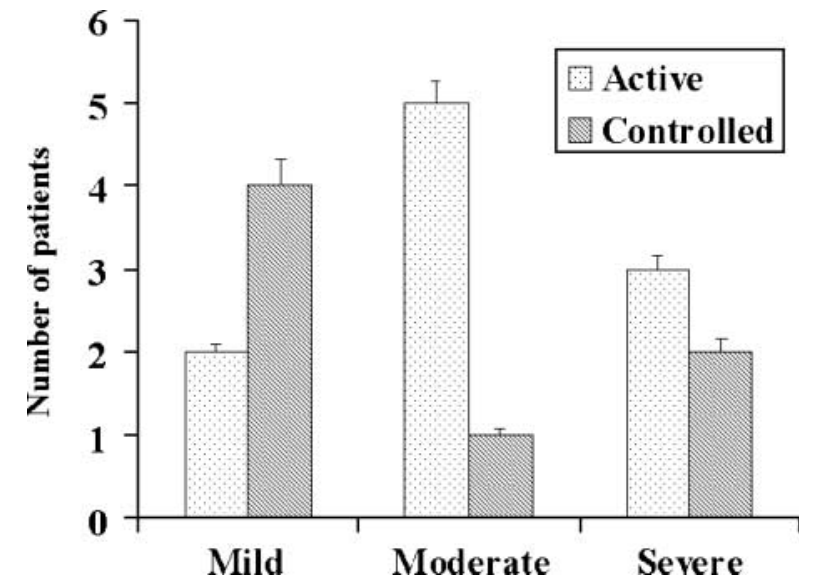

Figure 1 Severity of SAS in active and controlled acromegalic patients.

\section{Longitudinal study}

Six out of 10 patients with active acromegaly suffering from SAS repeated the polysomnography after achieving complete normalization (5 patients) or near complete normalization (one patient) of GH/IGF1 levels after a median controlled disease time of 3 years (range 1.4-4 years). In all but one, improvement of the AHI was observed, but none recovered (mean (s.D.) AHI 31.2 (16.4) vs 21.3 (18.2); HP 15.04 (6.1) events/h versus 9.6 (7.03) events/h, CA 2 (2.52) events/h versus 1.2 (1) events/h; Fig. 3). At the end of the study, two patients showed a change in the stage severity of SAS decreasing from moderate to mild. With the limitation due to the small number of patients, no correlation was found between the decrease of AHI, HP, CA and OA and that of GH/IGF1 levels and the remission time. The remaining four patients of this group did not repeat polysomnographic study because either disease was still active (nos

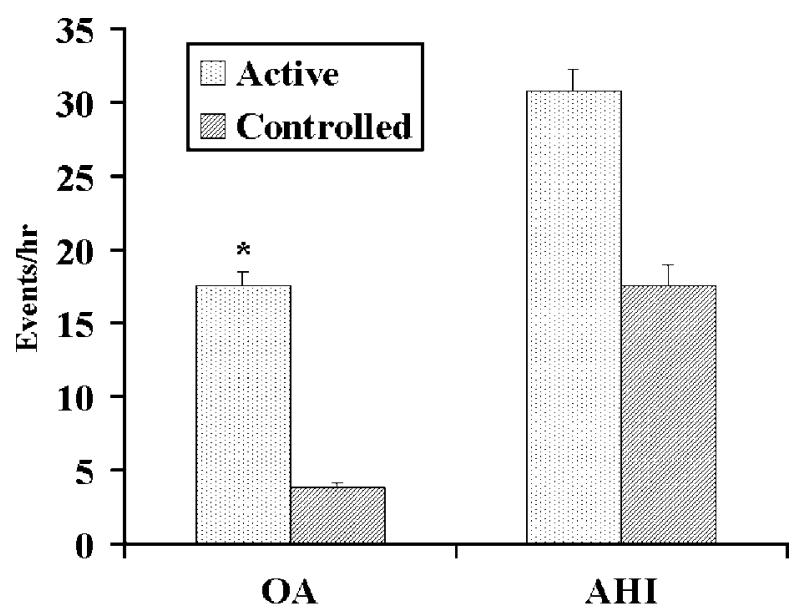

Figure 2 Obstructive apnoea (OA) and apnoea/hypopnoea index $(\mathrm{AHI})$ in active and controlled acromegalic patients.

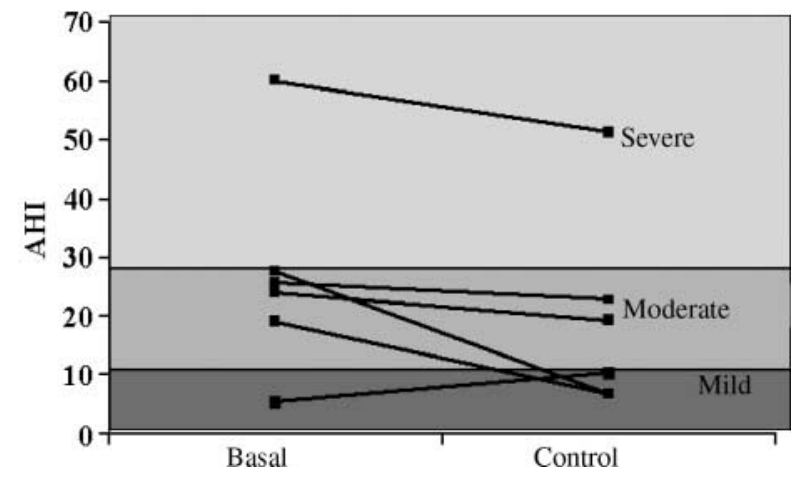

Figure $3 \mathrm{AHI}$ in six active acromegalic patients at baseline (Basal) and at follow-up (Control).

1 and 18) or they refused the examination (no. 14) or dropped out of the follow up (no. 4).

\section{Discussion}

Our data show that SAS is a frequent (47\%) comorbidity in the acromegalic population as a whole, confirming previously reported data (1-5). As expected, the prevalence of SAS was higher in the subgroup with active disease than in the subgroup in remission $(55 \%$ vs 39\%); in addition, SAS was less severe in patients of the latter subgroup.

The relative high prevalence of SAS in the acromegalic patients with inactive disease has already been observed by some authors who reported percentages ranging from 21 to $58 \%(4,14,15,28)$. Pelttari et al. (24) found persistence of nocturnal breathing abnormalities in 10 of 11 patients after pituitary $\mathrm{GH}$-adenoma resection, nine of whom were controlled at the time of the study.

Unfortunately, we could not perform baseline polysomnography during the previous active phase of the disease in the majority of inactive acromegalic patients with SAS so we cannot know whether the normalization of GH/IGF1 had at least reduced severity of SAS. In 6 out of 10 patients who could undergo polysomnography during the active phase of the disease and after normalization or near normalization of GH/IGF1, 1.4-4 years later, SAS subsided but did not disappear. In one patient this disorder persisted in spite of biochemical remission of the disease.

In our study, the way used to achieve disease remission does not seem to affect the persistence of SAS since the prevalence of patients suffering or free from this disorder was not significantly different in the subgroup who underwent surgical treatment alone and in the subgroup who received other treatments (somatostatin analogues and/or radiotherapy) in addition to the operation. In this regard, however, it has been recently reported that treatment with somatostatin analogues, associated with neurosurgery, leads to additional improvement of cardiac parameters, 
when compared with neurosurgery alone (33). Therefore, it cannot be ruled out that the same positive effect of medical therapy could be observed also on SAS parameters if the sample size of medically treated patients, either in active or in inactive phase, was larger.

It has been reported in literature $(14,16)$ a significant correlation between IGF1 levels, soft tissue swelling and tongue volume which could account for obstructive SAS. In this regard, no significant difference in GH/IGF1 levels could be observed between patients with and without SAS in both active and inactive groups. However, in a multivariate analysis, on the overall population, IGF1 levels were found to be an independent predictive factor for the development of SAS of obstructive origin. These discordant results may be due to the small number of patients in each subgroup and to the interference of other pathogenic factors involved in causing this complication. In fact, we found that the variables that predict SAS in our acromegalic population are the same which predict SAS in the general population, i.e. age, male gender and BMI $(34,35)$.

Moreover, we found that the estimated active disease duration was an independent predictor of SAS. Since the obstructive component of SAS was predominant, it can be assumed that the irreversible craniofacial deformations occurring in the previous active phase may account for the persistence of the apnoeic episodes after biochemical control, as already shown by some authors $(5,15,19,26)$. This hypothesis could also explain why, in our experience, the duration of disease remission among the subgroup of controlled acromegalic patients does not correlate with the presence of SAS. However, it could be supposed that periods of disease remission longer than what we observed could be necessary to completely reverse SAS.

These results have important clinical implications since they strengthen the need for early diagnosis and aggressive treatment of the disease.

In our series, diabetes or IGT were more prevalent in patients with SAS, especially in the severe forms. Although this was an expected finding, at least in active patients, due to the known diabetogenic effect of $\mathrm{GH}$ (6), a high prevalence of glycometabolic problems seems to be associated with SAS also in the controlled subgroup. In this latter, given the normal GH levels, it cannot be excluded that the impairment of insulin secretion due to somatostatin analogues may contribute to glucose metabolism derangement. In fact, among the patients receiving somatostatin analogues, four out of four patients in the active and four out of nine patients in the controlled group had either IGT or diabetes. Alternatively, it could be speculate, in agreement with current literature (36), that SAS itself may be independently associated with IGT and may predispose to the development of type 2 diabetes mellitus, by decreasing insulin secretion and increasing insulin resistance.

Diabetes has been reported to be an independent predictor of mortality in acromegaly (37) and also SAS could have a negative impact on life expectancy. Therefore, simultaneous presence of these two comorbidities, regardless of their causal link, should not be underestimated, even in cured acromegalic patients, and it should lead to additional specific treatments of both complications including diet, physical activity, antidiabetic drugs and, when indicated, Continuous Positive Airway Pressure (CPAP).

It is well known that SAS is associated with several cardiovascular disease conditions, even if a causal relationship remains to be proven (38) and long-term CPAP studies have shown several cardiovascular benefits (9). Although in our study, the presence of SAS does not seem to influence echocardiographic parameters, it is reasonable to suppose that improvement of SAS may contribute to better long-term cardiovascular prognosis also in acromegalic patients.

In conclusion, our data demonstrate that SAS can persist after recovery of acromegaly in a relative high percentage of patients. Several anthropometric, clinical and biochemical features of acromegaly can independently predict the risk of developing SAS. In particular, circulating IGF1 levels, BMI, male gender, age and disease duration are independently correlated with the presence of SAS. Moreover, diabetes or IGT was more prevalent in patients with SAS. Given the great relevance of disease duration on SAS occurrence, a rapid therapeutic effect seems to play a crucial role in preventing this severe complication.

We suggest that, considering the negative prognostic significance of this respiratory disorder, polysomnography should be performed at least once in every acromegalic patient, even if controlled, and it becomes mandatory in patients who are considered at high risk (elderly males, overweight, IGT, diabetic).

Furthermore, once the diagnosis of SAS is established, appropriate intensive treatment (somatostatin analogues, GH antagonist, antidiabetic, CPAP) and close monitoring of clinical parameters should be performed to minimize the clinical impact of SAS in acromegaly.

\section{Declaration of interest}

The authors declare that there is no conflict of interest that would prejudice the impartiality of this scientific work.

\section{Funding}

This research did not receive any specific grant from any funding agency in the public, commercial or not-for-profit sector.

\section{References}

1 Grunstein RR, Ho KY \& Sullivan CE. Sleep apnea in acromegaly. Annals of Internal Medicine 1991115 527-532.

2 Fatti LM, Sacchi M, Pincelli AI, Lavezzi E \& Cavagnini F. Prevalence and pathogenesis of sleep apnea and lung disease in acromegaly. Pituitary 20014 259-262. 
3 Weiss V, Sonka K, Pretl M, Dostalova S, Klozar J, Kambousek P, Marek J \& Haas T. Prevalence of the sleep apnea syndrome in acromegaly population. Journal of Endocrinological Investigation 200023 515-519.

4 Pekkarinen T, Partinen M, Pelkonen R \& Iivanainen M. Sleep apnoea and daytime sleepiness in acromegaly: relationship to endocrinological factors. Clinical Endocrinology 198727 649-654.

5 Hochban W, Ehlenz K, Conradt R \& Brandenburg U. Obstructive sleep apnoea in acromegaly: the role of craniofacial changes. European Respiratory Journal 199914 196-202.

6 Giustina A, Casanueva FF, Cavagnini F, Chanson P, Clemmons D, Frohman LA, Gaillard R, Ho K, Jaquet P, Kleinberg DL, Lamberts SW, Lombardi G, Sheppard M, Strasburger CJ, Vance ML, Wass JA \& Melmed S. Consensus: diagnosis and treatment of acromegaly complications. Journal of Endocrinological Investigation $2003 \mathbf{2 6} 1242-1247$.

7 Colao A, Ferone D, Marzullo P \& Lomabardi G. Systemic complications of acromegaly: epidemiology, pathogenesis and management. Endocrine Reviews 200425 102-152.

8 Patil SP, Schneider H, Schwartz AR \& Smith PL. Adult obstructive sleep apnea: pathophysiology and diagnosis. Chest $2007 \mathbf{1 3 2}$ 325-337.

9 Marin JM, Carrizo SJ, Vincente E \& Agusti AG. Long-term cardiovascular outcomes in men with obstructive sleep apneahypopnoea with or without treatment with continous positive airway pressure: an observational study. Lancet $20053651046-1053$.

10 Shamsuzzaman AS, Gersh BJ \& Somers VK. Obstructive sleep apnea: implications for cardiac and vascular disease. Journal of the American Medical Association 2003290 1906-1914.

11 Yaggi HK, Concato J, Kerman WN, Lichtman JH, Brass LM \& Mohsenin V. Obstructive sleep apnea as a risk factor for stroke and death. New England Journal of Medicine $20053532034-2041$.

12 Perks WH, Horrocks PM, Cooper RA, Bradbury S, Allen A, Baldock N, Prowse K \& van't Hoff W. Sleep apnoea in acromegaly. BMJ $1980 \mathbf{2 8 0} 894-897$.

13 Hart TB, Radow SK, Blackard WG, Tucker HS \& Cooper KR. Sleep apnoea in active acromegaly. Archives of Internal Medicine 1985 $145865-866$.

14 Rosenow F, Reuter S, Deuss U, Szelies B, Hilgers RD, Winkelmann W \& Heiss WDl. Sleep apnoea in treated acromegaly: relative frequency and predisposing factors. Clinical Endocrinology 199645 563-569.

15 Dostalova S, Sonka K, Smahel Z, Weiss V, Marek J \& Horinek D. Craniofacial abnormalities and their relevance for sleep apnoea syndrome aetiopathogenesis in acromegaly. European Journal of Endocrinology $2001 \mathbf{1 4 4} 491-497$.

16 Herrmann BL, Wessendorf TE, Ajaj W, Kahlke S, Teschler H \& Mann K. Effects of octreotide on sleep apnoea and tongue volume (magnetic resonance imaging) in patients with acromegaly. European Journal of Endocrinology 2004151 309-315.

17 Van Haute FR, Taboada GF, Corrêa LL, Lima GA, Fontes R, Riello AP, Dominaci M \& Gadelha MR. Prevalence of sleep apnea and metabolic abnormalities in patients with acromegaly and analysis of cephalometric parameters by magnetic resonance imaging. European Journal of Endocrinology 2008158 459-465.

18 Sze L, Schmid C, Bloch KE, Bernays R \& Brandle M. Effect of transsphenoidal surgery on sleep apnoea in acromegaly. European Journal of Endocrinology 2007156 321-329.

19 Isono S, Saeki N, Tanaka A \& Nishino T. Collapsibility of passive pharynx in patients with acromegaly. American Journal of Respiratory and Critical Care Medicine $199916064-68$.

20 Ip MSM, Tan KCB, Peh WCG \& Lam KSL. Effects of Sandostatin Lar on sleep apnoea in acromegaly: correlation with computerized tomographic cephalometry and hormonal activity. Clinical Endocrinology $2001 \mathbf{5 5}$ 477-483.

21 Mickelson SA, Rosenthal LD, Rock JP, Senior BA \& Friduss ME. Obstructive sleep apnea syndrome and acromegaly. Archives of Otolaryngology - Head E Neck Surgery $199411125-30$.
22 Main G, Borsey DQ \& Newton RW. Successful reversal of sleep apnoea syndrome following treatment for acromegaly, confirmed by polygraphic studies. Postgraduate Medical Journal 198864 945-946.

23 Piper JG, Dirks BA, Traynelis VC \& VanGilder JC. Perioperative management and surgical outcome of the acromegalic patient with sleep apnea. Neurosurgery 199536 70-74; discussion 74-75.

24 Pelttari L, Polo O, Rauhala E, Vuoriluoto J, Aitasalo K, Hyyppa MT, Kronholm E, Irjala K \& Viikari J. Nocturnal breathing abnormalities in acromegaly after adenomectomy. Clinical Endocrinology 199543 175-182.

25 Saeki N, Isono S, Nishino T, Iuchi T \& Yamaura A. Sleep-disordered breathing in acromegalics-relation of hormonal levels and quantative sleep study by means of bedside oximeter. Endocrine Journal $1999 \mathbf{4 6} 585-590$.

26 Tolis G, Angelopoulos NG, Katounda E, Rombopoulos G, Kaltzidou V, Kaltsas D, Protonotariou A \& Lytras A. Medical treatment of acromegaly: comorbidities and their reversibility by somatostatin analogs. Neuroendocrinology $200683249-257$.

27 Buyse B, Michiels E, Bouillon R, Bobbaers H \& Demedts M. Relief of sleep apnoea after treatment of acromegaly: report of three cases and review of the literature. European Respiratory Journal 199710 1401-1404.

28 Grunstein RR, Ho KK \& Sullivan CE. Effect of octreotide, a somatostatin analog, on sleep apnea in patients with acromegaly. Annals of Internal Medicine 1994121 478-483.

29 Giustina A, Barkan A, Casanueva FF, Cavagnini F, Frohman L, Ho K, Veldhuis J, Wass J, Von Werder K \& Melmed S. Criteria for cure of acromegaly: a consensus statement. Journal of Clinical Endocrinology and Metabolism 200085 526-529.

30 American Academy of Sleep Medicine Task Force Report. Sleeprelated breathing disorders in adults: recommendations for syndrome definition and measurement techniques in clinical research. Sleep 199922 667-689.

31 Sahn DJ, DeMaria A, Kisslo J \& Weyman A. The committee on M-mode standardization of the America Society of Echocardiography. Recommendations regarding quantification in M-mode echocardiography: results of a survey of echocardiography measurements. Circulation 197858 1072-1083.

32 Devereux RB \& Reichek N. Echocardiographic determination of left ventricular mass in man. Anatomic validation of the method. Circulation 197755 613-618.

33 De Marinis L, Bianchi A, Mazziotti G, Mettimano M, Milardi D, Fusco A, Cimino V, Maira G, Pontecorvi A \& Giustina A. The longterm cardiovascular outcome of different $\mathrm{GH}$-lowering treatments in acromegaly. Pituitary 200811 13-20.

34 Young T, Skatrud J \& Peppard PE. Risk factors for obstructive sleep apnea in adults. Journal of the American Medical Association 2004 291 2013-2016.

35 Tishler PV, Larkin EK, Schluchter MD \& Redline S. Incidence of sleep-disordered breathing in an urban adult population: the relative importance of risk factors in the development of sleepdisordered breathing. Journal of the American Medical Association $20032892230-2237$.

36 Punjabi NM \& Polotsky VY. Disorders of glucose metabolism in sleep apnea. Journal of Applied Physiology 200599 1998-2007.

37 Rajasoorya C, Holdaway IM, Wrightson P, Scott DJ \& Ibbertson HK. Determinants of clinical outcome and survival in acromegaly. Clinical Endocrinology 1994 41 95-102.

38 Wolk R \& Somers VK. Cardiovascular consequences of obstructive sleep apnea. Clinics in Chest Medicine 200324 195-205.

Received 23 July 2008

Accepted 29 July 2008 